4.

Derecho procesal 

Revista de Derecho

de la Pontificia Universidad Católica de Valparaíso

XXX (Valparaíso, Chile, $1^{\text {er }}$ Semestre de 2008)

[pp. 243 - 262]

\title{
LA OBTENCIÓN DE INFORMACIÓN PROBATORIA EN EL PROCESO CIVIL*
}

[Gathering and Access to Evidence in Civil Procedure]

\author{
RolF STÜRNER** \\ Universidad de Friburgo en Brisgovia
}

\begin{abstract}
Resumen
El conflicto entre el interés de una parte procesal en esclarecimiento de aquello respecto de lo cual tiene la carga de alegar y probar frente a los intereses de la contraparte y los terceros puede resolverse de dos maneras fundamentalmente: o no exponen su esfera privada o negocios en un proceso, o están sujetos a una carga o deber al servicio de intereses ajenos. Una alternativa es no afectar en lo posible a la contraparte o al tercero, debiéndose remitir la parte del proceso a su propio material procesal ("nemo tenetur contra se accusare" o "nemo contra se edere tenetur").
\end{abstract}

Palabras clave: Prueba - Carga de la prueba - Acceso a la información probatoria - Proceso civil.

\section{Abstract}

The conflicts between the selfinterest one party in civil procedure versus the other party and thirds be solved fundamentally in two ways: or they do not expose its private sphere or businesses in a process, or are subject to a load or to have to the service of other party's interests. Another alternative is as far as possible not to affect contraparte or to third, being due to send the part of the process to its own procedural fact finding and gathered evidence ("nemo tenetur contra se accusare" o "nemo contra se edere tenetur').

KeY wORDs: Evidence - Bourden of proof - Information gathering - Civil procedure.

* Este trabajo es parte de la investigación financiada por FonDECYT - Iniciación, titulada: "Estudio histórico, comparado y dogmático de las conductas no cooperativas de las partes en el proceso civil (rebeldía, contumacia, 'default')" N 11070054 , obtenido por el traductor. Traducción de Álvaro J. Pérez Ragone, LL.M. y Doctor en Derecho por la Universidad de Colonia (Alemania); Prof. de Derecho Procesal Civil en la Facultad de Derecho de la Pontificia Universidad Católica de Valparaíso. Dirección postal: Avda. Brasil 2950, Valparaíso, Chile. Correo electrónico: alvaro. perez ucv.cl

** Catedrático (Ordinarius) en la Universidad de Friburgo (Alemania); Doctor en Derecho; Visiting Professor Harvard Law School (invierno 2001 y otoño 2003); ministro de los Superiores Tribunales de Karlsruhe y Baden - Württemberg (Alemania). 


\section{EL PUNTO DE PARTIDA DE LA ANTIGUA “ZIVILPROZESSORDNUNG” CON INFLUENCIA TRADICIONAL}

\section{Las dos alternativas fundamentales.}

Quien inicia un proceso, teniendo en cuenta que debe probar sus alegaciones y enervar las de la contraparte, ha de partir en primer lugar fundándose en el material fáctico y probatorio que se encuentra bajo su control. Pero frecuentemente se ha de remitir al soporte probatorio que pertenecen a la esfera del adversario o de un tercero. El conflicto entre el interés de la parte procesal para el esclarecimiento de aquello respecto de lo cual tiene la carga de alegar y probar versus los intereses enfrentados de la contraparte y terceros puede resolverse de dos maneras fundamentalmente: o no exponen su esfera privada o negocios en un proceso, o son sujetos a una carga o deber al servicio de intereses ajenos. Una alternativa es no afectar en lo posible a la contraparte o al tercero, debiéndose remitir la parte del proceso a su propio material procesal ("nemo tenetur contra se accusare" o "nemo contra se edere tenetur ") pudiendo perturbar al adversario o a un tercero sólo excepcionalmente. La otra alternativa es imponer la carga plenamente en ambos puntos de partida, y sólo establece excepciones el sentido de fundamentos plausibles justificados para no prestar colaboración.

\section{El modelo de "autoayuda" del antiguo ZPO.}

La Zivilprozessordnung alemana (ZPO. u "Ordenanza sobre el proceso civil" ["Código Procesal Civil"]) se inclina en su estructura inicial, como lo establecieron las leyes del Imperio, por una solución cuya finalidad es, en lo posible, no perturbar a la contraparte o a terceros ${ }^{1}$.

a) El terreno previo del proceso. Antes del inicio del proceso las partes, contrapartes y terceros tienen solo reducidas acciones para obtener información fundada en el derecho material, sea para aclaración, presentación y exhibición de documentos. Sea para inspección de objetos, lo que supone especiales supuestos y requisitos jurídicos ${ }^{2}$. Así surge la posibilidad de sanciones en forma de costos procesales para los deberes de información de la contraparte en casos excepcionales y determinados ${ }^{3}$. Los deberes

\footnotetext{
${ }^{1} \mathrm{Al}$ respecto ver STÜRner, Rolf, Die Aufklärungspflicht der Parteien des Zivilprozesses (Tübingen, 1976), p. 380.

${ }^{2}$ Ver especialmente los $\$ \$ 666,809,810$ BGB. (Bürgerliches Gesetzbuch = "Código Civil”); en relación con otras disposiciones legales aplicables, ver: STÜRNER, Rolf, Aufklärungspflicht, cit. (n. 1), pp. 287 ss.

${ }^{3}$ En especial $\$ 93$ ZPO.
} 
probatorios preprocesales tienen adrede solo una reducida regulación en el ámbito de la incumbencia probatoria ${ }^{4}$.

b) Medios para el esclarecimiento en el proceso. Aun cuando en el proceso la contraparte deba manifestarse sustancialmente con la amenaza de sanción bajo la forma de confesión ficta ${ }^{5}$, el control de veracidad existe, aunque inicialmente solo en forma subsidiaria y mutilada, dentro de la estructura del juramento, en un momento dejado de lado, luego reinsertado. Recién con posterioridad el legislador se decide por un real control de la verdad mediante la declaración (subsidiaria) de parte ${ }^{6}$ El deber de la contraparte consistente en exhibir documentos u objetos para su inspección remite mayoritariamente al derecho material, o se encuentra carente de regulación ${ }^{7}$. En relación con los terceros, la ley exige incluso una demanda fundada en el derecho material ${ }^{8}$, pero sin establecer una sanción procesal como sí existe en relación a la contraparte?. Por el contrario el deber testimonial del tercero es amplio, sin embargo limitado a la declaración oral sin deber alguno de preparación ${ }^{10}$, no existiendo declaraciones por escrito. La preparación mediante abogados perjudica la credibilidad ${ }^{11}$. Allí donde el tribunal, de oficio, ordena diligenciar una prueba permanece el interrogante sin respuesta. Interrogante que se centra es dilucidar si para la producción oficiosa de una prueba es suficiente esa resolución en comparación con la prueba requerida a solicitud de parte ${ }^{12}$. Cada vez más frecuente impone el HGB. ("Código de Comercio") para los comerciantes -según del modelo francés y en casi toda Europa-, el

${ }^{4} \$ \$ 444 \mathrm{ZPO}$.

${ }^{5} \$ 138$ apartados 2 y 3 ZPO.

${ }^{6}$ En relación a esta parte de la historia del proceso, ver: Coester - WaLtjen, Dagmar, Parteiaussage und Parteivernehmung am Ende des 20. Jahrhunderts, en En Zeitschrift für Zivilprozess) 113 (2000), pp. 269 ss.; Oвеrнамmer, Paul, Parteiaussage, Parteivernehmung und freie Beweiswürdigung am Ende des 20. Jahrhunderts, en Zeitschrift für Zivilprozess 113 (2000), pp. 295 ss.; Polyzogopoulos, Konstantin, Parteianhörung und Parteivernehmung (Berlín, 1976), pp. 41 ss.; STürner, Rolf, Die Partei als Beweismittel im europäischen Zivilprozeß, in Festschrift Ishikawa (Berlin, 2001), pp. 529 ss.

${ }^{7} \$ \$ 371$ ss. ZPO. en su antigua redacción.

${ }^{8} \$ \$ 428$ ss. ZPO. en su antigua redacción.

${ }^{9} \$ 427 \mathrm{ZPO}$.

${ }^{10} \$ \$ 373$ ss. ZPO. en su antigua redacción.

${ }^{11}$ En relación a esta tradicional visión, ver especialmente: Timmerbeil, Sven, Witness Coaching und Adversary System (Tübingen, 2004), pp. 114 ss.; Murray, Meter - STürner, Rolf, German Civil Justice (North Carolina, 2004), pp. 294 - 295.

${ }^{12}$ En forma completa ya en STÜRNER, Rolf, Aufklärungspflicht, cit (n. 1), pp. 67 ss. 
deber de exhibir los libros de comercio ante orden judicial, incluso sin un especial y calificado requisito de derecho material ${ }^{13}$.

\section{El ideal de justicia del modelo tradicional de "autoayuda".}

a) La limitada relación con los ideales de responsabilidad de las partes y del juez. La elección entre una u otra alternativa y, con ello la decisión por el modelo de "autoayuda "tiene indirectamente que ver en todos los casos con la distribución de roles entre las partes y el juez en el proceso. Ello igualmente se vincula con la pregunta de la distribución de la responsabilidad para la dinámica e impulso del proceso entre las partes y el tribunal. Tanto para el principio de aporte de prueba por las partes como para el inquisitivo, la parte que no tiene la carga de la prueba puede ser de alguna manera en menor o mayor medida sujeta a la carga de impulso. Así en el caso del principio inquisitivo en el proceso penal, si no hay ninguna colaboración activa por parte del imputado o acusado, ello podría ser de alguna manera sancionado ${ }^{14}$. Pero, en realidad, recién cuando las pruebas de la fiscalía requieran ser desvirtuadas, es cuando se exige el ejercicio de la carga de la dirección probatoria en cabeza del imputado. De la misma manera lo requiere el proceso civil angloamericano con su fuerte principio de disposición de las partes contrario a la visión tradicional, siendo que se requiere mucha mayor colaboración de parte y terceros que el sistema procesal civil continental de dominio del juez ${ }^{15}$. Es decir no es determinante el ideal de la responsabilidad de las partes o del juez para una justa decisión que engloba el deber de cooperación para la obtención y aporte de la información probatoria ${ }^{16}$.

b) Verdad material y justicia. Mucho más decisiva es la relación

${ }^{13} \$ \$ 45$ ss. HGB. [Handelsgesetzbuch = "Código de Comercio"] en su antigua redacción; actualmente en $\$ \$ 258$ ss. HGB. (1985).

${ }^{14}$ Especialmente $\$ \$ 136$ inciso 1 párrafo. 2, 243 inciso $4^{\mathrm{o}}$ párrafo 1 StPO. (Strafprozessordnung o "Código Procesal Penal"); Roxin, Klaus, Strafverfahrensrecht (25a edición, München, 1998), pp. 103 ss., 200 s.; BverfGE. pp. 56, 37 ss.

${ }^{15} \mathrm{Al}$ respecto Friedenthal, Jack - Kane, Mary Kay - Miller, Arthur, Civil

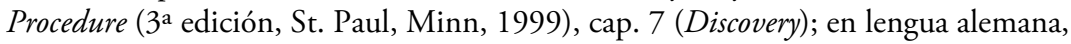
ver: Sснаск, Haimo, Einführung in das US-amerikanische Zivilprozessrecht (3a edición, München, 2003), pp. 45 ss. (sub V, 4); para una comparación Murray, Meter - STÜrNER, Rolf, cit. (n. 11), pp. 239 ss.

${ }^{16}$ Otro punto de vista ver en Stein, Friedrich - Jonas, Martin - Leipold, Dieter, Comentar zur Zivilprozessordnung (21 a edición, Tübingen, 1993), $\$ 138$ No 22; Arens, Peter, Zur Aufklärungspflicht der nicht beweisbelasteten Partei im Zivilprozeß, en Zeitschrift für Zivilprozess 96 (1983), pp. 1 ss.; Lüke, Wolfgang, Die Zuständigkeitsprüfung nach dem EuGV., en Gedächtnisschrift Arens (München, 1993), pp. 1 ss., 11 ss., 13. 
con la verdad material. Mientras más fuerte se inserten la contraparte o terceros, mayor será la cercanía con el resultado de determinación de los hechos de la verdad material ${ }^{17}$. Mientras menor sea el círculo para la obtención de un medio de prueba, mayor será entonces el distanciamiento en relación a la verdad material. Ello con las consecuencias de que el derecho material no pueda efectivizarse en absoluto, ya que de acuerdo a las reglas de la prueba su aplicación será parcialmente modificada en su contenido original ${ }^{18}$. El sentimiento jurídico profano se inclina más bien a unir el derecho con la verdad material, de acuerdo a lo cual la cercanía del sistema de jurados angloamericano se abre lo máximo posible en relación a todos los medios de prueba ${ }^{19}$. El jurista "erudito" puede contrariamente reconocer y aceptar más claramente, que el descubrimiento de la verdad a favor de los intereses de personas privadas puede tener límite en los derechos de libertad de otros ciudadanos. El proceso alemán ha determinado inicialmente este límite en beneficio de la libertad de potenciales partes intervinientes y de la verdad.

c) Orígenes de la reserva frente al ideal de la "verdad material". En muy pequeño alcance se consideró la rigurosidad en este punto a tratar. Probablemente fue la reacción liberal contra las tendencias del estado de bienestar del proceso prusiano ${ }^{20}$ el que se articuló de esta forma y por ende resaltó el pensamiento civil procesal de la "autoayuda". Quizás, con el reciente descubrimiento de la libre valoración de la prueba sirvió de marco para evitar en lo posible la formulación de nuevas normas que establezcan sanciones para la cooperación de las partes dejando a éstas en libertad. Siendo que se sujetarían de todas formas al ejercicio de la libre apreciación de la prueba ${ }^{21}$. En todos los casos las tendencias fueron claras, a saber no garantizar a las partes entre ellas más derechos que los que tendrían sin un proceso. Para terceros solo se estableció el deber como testigos, en tanto deberes como ciudadanos del Estado ${ }^{22}$, lo que debía ser el punto de

${ }^{17}$ STÜRner, Rolf, Aufklärungspflicht, cit. (n. 1), pp. 29 ss., 31 ss., 48 ss.

${ }^{18} \mathrm{Al}$ respecto: Rosenberg, Leo - Schwab, Karl - Heinz - Gottwald, Peter, Zivilprozessrecht (16a edición, München, 2004), $\$ 115$ VI, p. 791.

${ }^{19}$ En relación con la vinculación entre jueces legos y verdad material, ver: STÜRNER, Rolf, The Principles of Transnational Civil Procedure. An Introduction to Their Basic Conceptions, en Rabels Zeitschrift ausländisches und internationales Privatrecht 69 (2005), pp. 201 ss., 237 ss., 239.

${ }^{20}$ En relación con los motivos, ver: especialmente en HaHn, Carl, Die gesamten Materialien zu den Reichsjustizgesetzen ( $2^{\text {a }}$ edición, Berlin, 1881, reimpresión Berlin, 1983), II, 1, p. 114.

${ }^{21}$ Sobre los motivos, ver en Hahn, cit. (n. 20), p. 275.

${ }^{22}$ Nuevamente sobre los motivos, ver: HaHN, cit. (n. 20), p. 325, con el intento sentar fundamentos completos a las en relación al deber de esclarecimiento de terceros. 
partida para el nuevo proceso según este principio. Lo que, por cierto era inconsecuente dentro del contexto pleno, ya que no había otros deberes procesales de colaboración en que titularizaran los terceros.

\section{EL DESARROLLO POSTERIOR \\ DE LA OBTENCIÓN DE INFORMACIÓN PROBATORIA POR LA JURISPRUDENCIA}

\section{Breve caracterización.}

La jurisprudencia ha liberado de su prurito la regla legal de la obtención de información probatoria e igualmente ha extendido a todas las áreas del derecho los deberes de información. Sin embargo no se ha desarrollado un sistema totalmente cerrado, sino más bien una serie de mecanismos aislados que sirven de instrumentos, de modo que el juez pueda acceder a la información. Este desarrollo ya se describió en otra oportunidad ${ }^{23}$, de modo que en esta oportunidad debieran bastar solo unas breves palabras. En la etapa preparatoria del proceso la jurisprudencia logró construir con especial designación pretensiones de información judicial. Lo que se manifestó en forma amplia frente a potenciales deudores o demandados y en forma muy singular y restringida frente a terceros ${ }^{24}$. El establecimiento de deberes de información preprocesales sancionados con determinados costos comprende ampliaciones aisladas y excesivamente prudentes. ${ }^{25}$ Jurisprudencialmente se establecieron claramente deberes preprocesales de conservación de documentación y pruebas, siendo que su vulneración negligente conlleva sanciones en forma de consecuencias probatorias desventajosas $^{26}$. La jurisprudencia -en casos de comprensible desconocimiento de la parte que tiene la carga de la alegación- se inclina en el proceso a transferir a la contraparte un deber de aclaración en relación a los hechos que sustancialmente lo requieran y sea de plausible conocimiento general.

${ }^{23}$ En forma completa STÜRNER, Rolf, Aufklärungspflicht, cit. (n. 2), pp. 134 ss.; más aun ver últimamente en Rosenberg, Leo - Schwab, Kart-Heinz - GotTwald, Peter, cit. (n. 18), $\$ 108$, pp. 737 ss.

${ }^{24}$ Como ejemplo importante BGHZ [= "Bundesgerichshof in Zivilsachen" = "decisiones de la Corte Federal en asuntos civiles"] 125, 322 ss. "Cartier - Armreif"); BGH, en Neue Juristische Wochenschrift (1995), p. 1.965 ("Schwarze Liste ["Lista Negra"]).

${ }^{25} \mathrm{Al}$ respecto, en especial: Breyer, Michael, Kostensanktionierte Steuerung des Zivilprozesses (Tübingen, 2006), \$6 B II 2 b y C II 1; con mayor detalle, ver: STÜRNER, Aufklärungspflicht, cit. (n. 1), pp. 270 s.

${ }^{26}$ Últimamente BGH, en Neue Juristische Wochenschrift (2004), p. 222; RosenBerg - Schwab - Gottwald, cit. (n. 18), \$114 II 6, no. 20 ss.; Stürner, $A u$ fklärungspflicht, cit. (n. 1) $\$ 10 \mathrm{IV}$ y V, S. 156 ss., 162 ss. 
Ello justifica que el deber de información deba recaer en quien la tiene y conoce ${ }^{27}$. Allí donde la redacción original de la ZPO. guardó silencio sobre el deber de colaboración de la contraparte, la libre apreciación de la prueba surgió -y como ya se aclaró históricamente en forma legítima- y se demostró como valiosa enemiga de la pasividad para esclarecer las alegaciones en el proceso. Así se convirtió en una puerta para exigir la cooperación, ello aun cuando no surja sin cuestionamiento un ampliado deber de esclarecimiento (exhibición y visita en la prueba de inspección ${ }^{28}$, identificación de testigos ${ }^{29}$, liberación de deberes de secreto profesional ${ }^{30}$, inspección corporal para informes médicos ${ }^{31}$, etcétera).

\section{La elaboración dogmática.}

La discusión en torno al tratamiento histórico de este desarrollo se mueve entre las dos razonables alternativas fundamentales cuyas puertas de ingreso ya se desarrollaron. Quien se incline por el interés de esclarecimiento de las partes procesales y con ello hacia el mejor posible acceso a la verdad material, fundamentalmente prefiriéndola sobre los pocos específicos intereses de libertad de los intervinientes procesales, ve en el desarrollo de esta jurisprudencia una valiosa tendencia hacia un deber básico de esclarecimiento procesal. Deber que solo podría ser excepcionalmente limitado en supuestos específicos en pos de los intereses de libertad de las partes procesales ${ }^{32}$. Quien por el contrario desea mantenerse atado

${ }^{27}$ Por ejemplo BGH, en Neue Juristische Wochenschrift-RR (2004), p. 989; Neue Juristische Wochenschrift (1999), pp. 1404, 1406; Neue Juristische Wochenschrift (1990), pp. 3151, 3152; y al respecto: STüRner, Rolf, Anmerkung zum Urteil des BGH v. 11.6.1990 (Aufklärungspflicht der nicht beweisbelasteten Partei im Zivilprozeß), en Zeitschrift für Zivilprozess 104 (1991), pp. 208 ss., 211; en la misma dirección, pero a nivel procesal notoriamente impreciso BverfG., en Neue Juristische Wochenschrift (2000), p. 1483.

${ }^{28}$ Por ejemplo: BGH LM No 28 zu $\$ 286$ (B) ZPO.

${ }^{29}$ BGH Neue Juristische Wochenschrift (1960), p. 821.

${ }^{30}$ BGH NJW (Neue Juristische Wochenschrift)1972, 1131 y s.; 1967, 2012.

${ }^{31}$ RGZ. 60, 147 en Juristische Wochenschrift (1905), p. 201; BGH VersR. (1958), p. 768.

${ }^{32}$ Así, siguiendo el punto de vista de STÜRNER, Aufklärungspflicht, cit. (n. 1), pp. 29 ss., 85 ss.; coincidente en especial: Henckel, Wolfram, Wandel des Prozessverständnisses vom liberalen zum sozialen Zivilprozess? en Zeitschrift für Zivilprozess 92 (1979), p. 100; Schlosser, Peter, Zivilprozessrecht (2a edición, München, 1991), I, No 426 ss.; El mismo, Die lange deutsche Reise in die prozessuale Moderne, en Juristen Zeitung (1991), p. 599; Koller, Versicherungsrecht (1990), pp. 553, 558; GrUNSKY, Wolfgang, Zivilprozessrecht (12a edición, Tübingen, 2006), № 43, p. 31, siguiendo a Baur, F., Zivilprozessrecht (6a edición, Tübingen, 1989); Schmidt, Joachim, Alternativ-Kommentar ZPO. (Saarbrücken, 1987), $₫ 138$ No 5, $\$ 138$ n. 11; STADLER, 
al sistema de "autoayuda" de la ZPO., ve en este desarrollo de la jurisprudencia en realidad la conformación de grupos de casos excepcionales que modifican o rompen la regla esencial del "nemo tenetur se accusare"33. La jurisprudencia por su lado apenas participó en esta discusión dogmática, más bien se redujo a repetir viejas fórmulas y simultáneamente a construir nuevos grupos de casos donde aceptaba el deber de esclarecimiento, sin que claramente se haya manifestado sobre la regla y las excepciones ${ }^{34}$.

\section{DERECHO COMPARADO Y SU ARMONIZACIÓN}

Con su gran apego al texto originario de la ZPO. y con la construcción ya poco clara de grupo de fallos, Alemania se ha alejado más y más del desarrollo europeo e internacional.

\section{Reformas en los paises vecinos europeos.}

Esta corriente ya había sido validada tempranamente en relación al vecino francés con su Nouveau Code de Procédure Civile de 1976. Lo que

Astrid. Schutz des Unternehmensgeheimnisses im deutschen und US-amerikanischen Zivilprozess und im Rechtshilfeverfahren (Tübingen, 1989), pp. 80 ss.; Lorenz, Stephan, Die Neuregelung der pre-trial-Discovery im US-amerikanischen Zivilprozessrecht: Inspiration für den deutschen und europäischen Zivilprozess? en Zeitschrift für Zivilprozess 111 (1998), pp. 35 ss., 57; Katzenmeier Christian, Aufklärungs-Mitwirkungspficht der nicht beweisbelasteten Partei im Zivilprozess, en Juristen Zeitung (2002), pp. 533 ss.; Lang, Jochanes, Die Aufklärungspflicht der Parteien des Zivilprozesses vor dem Hintergrund der europäischen Rechtsvereinheitlichung (Berlin, 1999), pp. 264 ss.; Rотн, Herbert, Die Vorschläge der Kommission für ein europäisches Zivilprozeßgesetzbuch. Das Erkenntnisverfahren, en Zeitschrift für Zivilprozess 109 (1996), pp. 271 ss., 291 s.; El MISMO, Rezension, en Zeitschrift für Zivilprozess 113 (2000), pp. 503, 506; Greger, Reinhard, Vom "Kampf ums Recht" zur Zivilprozess der Zukunft, en Juristen Zeitung (1997), pp. 1077, 1080; El Mismo, Justizreform? Ja, aber..., en Juristenzeitung (2000), pp. 842, 847; WATERSTRAat, Daniel, Informationspflichten der nicht risikobelasteten Partei im Zivilprozess, en Zeitschrift für Zivilprozess 118 (2005), pp. 459 ss.; Haedicke, Maximilian, Perspektiven des gaeistigen Eigentums, Festschrift Schricker (München, 2005), pp. 19 ss.; WAGNER Gerhard, Europäisches Beweisrecht. Prozeßrechtsharmonisierung durch Schiedsgerichte, en Zeitschrift für Europäisches Privatrecht (2001), pp. $467 \mathrm{~s}$.

${ }^{33}$ Así Stein - Jonas - Leipold, cit. (n. 16) $\$ 138$ No 22a ss.; Rosenberg Schwab - Gottwald, cit. (n. 18), \$108 III 2, pp. 740 ss.; Prütting, Hanns, Gegenwartsprobleme der Beweislast (München, 1983), pp. 137 ss.; LükE, Gerhard., Der Informationsanspruch im Zivilrecht, en Juristische Schulung (1986), pp. 2-3; Arens, Peter, Zur Aufklärungspflicht der nicht beweisbelasteten Partei im Zivilprozess, en Zeitschrift für Zivilprozess 96 (1983), pp. 1 ss.

${ }^{34}$ En especial BGH, en Neue Juristiasche Wochenschrift (1990), pp. 3151 ss.; crítico STÜRNER, en Zeitschrift für Zivilprozess, cit. (n. 27), pp. 208 ss. 
se confirma luego y más fuertemente en los casos de las reformas española e inglesa y también en relación a Italia en sus sucesivas modificaciones ${ }^{35}$. Todos estos ordenamientos procesales permiten en mayor o menor medida el acceso pleno a los medios de prueba de la contraparte y terceros, siempre que no existan motivos justificados para negarse. No es ninguna coincidencia que el Tribunal Europeo de Derechos Humanos haya declarado en 1993 que: "[...] le droit communautaire n'impose pas le respect du droit de ne pas témoigner contre soi-même dans une procédure civile ${ }^{\mathrm{s} 6}$.

\section{El temor al modelo americano.}

En la discusión europea y especialmente alemana ha sido decisivo el temor al "pretrial discovery", de impronta estadounidense, para el esclarecimiento de los hechos ${ }^{37}$. Fue incluso el motivo de por qué no se introdujo en el $61^{\circ}$ Congreso Alemán de Derecho en Leipzig, celebrado en 1996, un deber general de esclarecimiento para fortalecer la primera instancia ${ }^{38}$. Sin embargo el difuso temor frente a la ampliación del deber de esclarecimiento se asienta en un error fundamental: no es en menor medida la extensión de los deberes de esclarecimiento, lo que podría conducir al exceso de escudrińamiento o una investigación más incisiva para obtener información ("fishing expedition"). En realidad más bien fueron

${ }^{35}$ En relación al desarrollo en el derecho comparado ver en especial ScHLosSER Peter, Die lange deutsche Reise in die prozessuale Moderne, en Juristen Zeitung (1991), pp. 599 ss.; Wagner, cit (n. 32), 467; Roth, cit. (n.32) pp. 271 ss., 291 s.; LANG, Aufklärungspflicht, cit. (n. 32), passim; STüRNER, Rolf, Beweislastverteilung und Beweisführungslast in einem harmonisierten europäischen Zivilprozeß, en Festschrift Stoll (Tübingen, 2001), pp. 691 ss., 699 s., con una completa justificación; EL MISMO, en Rabels Zeitschrift, cit. (n. 19), 201 ss., 233 s. en detalle.

${ }^{36}$ TEDH, 10.11 .1993 - C 60/92 Dalloz 1994, p. 197 ("Otto vs. Postbank“).

${ }^{37}$ Ver Gruber, Ulrich - KIessling, Erick, Die Vorlagepflichten der SS $142 \mathrm{ff}$. ZPO. nach der Reform 2002, en Zeitschrift für Zivilprozess 116 (2003), pp. 305 ss.; Zeкоll, Joachin - Bolt, Jan, Die Pflicht zur Vorlage von Urkunden im Zivilprozess, en Neue juristische Wochenschrift (2002), pp. 3129 ss.; LeIPOLd, en Festschrift Gerhard (Tübingen, 2004), pp. 563 ss.; STADler, Astrid, Gruppenklagen in den Mitgliedstaaten der Europäischen Gemeinschaft, en Festschrift Beys (Atenas, 2003), II, pp. 1625, 1627; Trittmann, Rolf - Leitzen, Mario, Haager Beweisübereinkommen und pre-trial discovery, en Iprax. Praxis des Internationalen Privat- und Verfahrensrechts (2003), pp. 7, 11 s.; LüPKe - Müller, Pre-Trial Discovery of Documents “ und $\$ 142$ ZPO., en Neue Zeitschrift f. das Recht der Insolvenz und Sanierung (2002), pp. 588 ss.; Triebel, Volker - Zons, Jan, Befragung von Zeugen vor dem Hearing in Unternehmensinsolvenzrechts durch den Enterprise Act, en Recht der Internationalen Wirtschaft 3(2002), núm. 3 parte 12, pp. 26 ss.

${ }^{38}$ Así la propuesta de GotTwald, Peter, Gutachten der 61. Deutschen Juristentag (1996), pp. A 15-21. 
las pocas exigencias en relación a sus requisitos, a saber: la sustanciación de los hechos alegados y la individualización de los medios de prueba. Mientras el sistema continental y en el último tiempo el proceso inglés establece elevados requisitos, paralelamente el proceso en USA. los ha disminuido en gran medida, tanto que es suficiente que los hechos o medios de prueba tengan alguna vinculación evidente con la litis ("relevant to the case"). No es en realidad la ampliación del umbral de los medios de esclarecimiento lo que conduce al exceso -lo que es demostrado en la experiencia del resto de los reformados sistemas procesales continentales-, sino más bien las escasas exigencias al inicio de la recopilación procesal del material probatorio ${ }^{39}$.

\section{Información probatoria en la etapa previa al proceso: el sistema inglés} de "pre-action-protocols" y "witness statements".

El nuevo proceso civil inglés ha avanzado aun más en la etapa previa al proceso. Con las "pre-action-protocols" ha establecido deberes de información con sanciones procesales en costos económicos concretos, lo que motiva a brindar la información sobre material fáctico y probatorio incluso antes del inicio del proceso para poder evitar y ahorrarse un litigo ${ }^{40}$. Las declaraciones de testigos pueden efectuarse en forma escrita como "witness statements" e incluso ser intercambiadas antes del proceso, lo que en muchos casos puede ocasionar mayor claridad y hasta una saludable desilusión ${ }^{41}$.

\section{EL ESFUERZO ALEMÁN POR LA REFORMA}

La reforma alemana del año 2002 ha aumentado y fortalecido en forma significativa los medios procesales para la obtención de información. Incluso ya antes el legislador había establecido medidas para el mejoramiento de la obtención de la información, lo que se manifestó no solo en la ZPO., sino además en el derecho material.

\section{Etapa preprocesal.}

En la etapa preprocesal se establecieron legislativamente en algunas

${ }^{39} \mathrm{Al}$ respecto STÜrner, Rolf, en Rabels Zeitschrift cit. (n. 19), pp. 201 ss., 234; en la misma posición LeIPOLD, Dieter, en Festschrift Gerhard (Tübingen, 2004), pp. 563 ss., 569 ss.

${ }^{40}$ Ver Andrews, Neil, Englisch Civil Procedure (Oxford, 2003), No 26, pp. 63 ss.

${ }^{41}$ Ver Zuckerman, Adrian, Civil Procedure (Oxford, 2003), cap. 19, pp. 600 SS. 
áreas de pretensiones de información fundadas en el derecho material. Ello rige para la responsabilidad ambiental ( $\$ \$ 8$ ss. UmweltHG.) ("Ley de responsabilidad ambiental”), para el derecho de los medicamentos ( $\$$ 84a AMG.) ("Ley de medicamentos) o de la técnica de manejo de genes ( $\$ 35$ GenTG.) ("Ley de técnica genética"), así también como en el campo de la piratería o copia de productos ( $\$ \$ 140 \mathrm{~b}$ PatG. ("Ley de patentes"), 24b GebrMG. ("Ley de modelos de utilidad"), 19 MarkenG. ("Ley de marcas"), 101a URNG. ("Ley de autoría intelectual"). La posibilidad de un resguardo preprocesal mediante el aseguramiento de prueba igualmente ha sido ampliado por el legislador (\$\$ 485 ss. ZPO. 1990).

\section{Deber interno de colaboración procesal.}

Pero es posible divisar igualmente ya durante el proceso la tendencia clara al fortalecimiento de las posibilidades para la consecución del esclarecimiento. Se introdujeron disposiciones relativas a la declaración provisoria de testigos en forma escrita ( $\$ 377$ párr. 3 ZPO. 1990) y para permitirles mayor desenvolvimiento la posibilidad de traer consigo documentos que faciliten su declaración ( $\$ 378$ ZPO. 1990). Esto por cierto no debe confundirse con la regla más sofisticada que establece el deber de acompañar o exhibir materialmente documentos al proceso ${ }^{42}$. El deber de presentar documentos u objetos para efectivizar su inspección fue establecido en forma definitiva por la reforma 2002. Así el tribunal puede ordenar, a petición de parte o de oficio, la presentación de documentos u objetos para su inspección que estén en poder de la contraparte o terceros -según el texto legal-incluso pudiéndose ordenar medidas coercitivas contra estos últimos (\$\$ 142-144, $371 \mathrm{ZPO}$. 2002).

\section{La controversia sobre la interpretación de las dos alternativas reguladoras.}

Sin embargo -en forma poco feliz- el legislador dejó las viejas normas que limitan el deber de presentación y de sumisión para tolerar la inspección en caso de negativa de la parte para la producción de la prueba, por cierto justamente a la par de las normas que regulan en forma nueva la prueba de oficio ( $\$ \$ 371,422$ ss. ZPO.). De esta forma los conflictos y problemas hermenéuticos pueden ya verse como preprogramados. $\mathrm{O}$ hay una limitación de los $\$ \$ 142$ ss. ZPO. a la par de los $\$ \$ 371,422$ ss. ZPO. y entonces se aplican las antiguas disposiciones de deber de cooperación ${ }^{43}$. O se opta por otra alternativa interpretativa a saber, la de una posibilidad

${ }^{42}$ Es reglada por los $\$ \$ 378$ párr. 1 pp. 2, 142 ZPO. 2002.

${ }^{43} \mathrm{Al}$ menos en los resultados parcialmente coincidente Leipold, cit. (n. 39), pp. 563 ss., 580 ss. 
ampliada para la obtención oficiosa de información probatoria con el resultado pensable que, disuelto el deber de colaboración dentro de la discrecionalidad del juez, no existen sin embargo requisitos limitantes o criterios para su ejercicio. Ello en caso que no quiera partirse de un deber fundamental de cooperación sujeto a las limitaciones de acuerdo a casos legítimos aun contra intereses invocables ${ }^{44}$. La tendencia internacional se corresponde con una interpretación cercana y amigable con el deber de esclarecimiento ${ }^{45}$.

\section{Derechos a la negativa de colaboración.}

En forma correcta, la reforma ha reconocido la importancia de garantizar, en cada forma de obtención de información, correspondientes derechos para negarse a colaborar ( $\$ \$ 142$ par. 2 oración 1, 144 par. 2 oración $1^{\mathrm{a}} \mathrm{ZPO}$.). Ello se debe nuevamente a la adopción de un derecho material cercano a amplios deberes de colaboración desperdigados, ya que esta limitación no debiera ser necesaria en una simple remisión al derecho material. La sanción contra la parte debiera residir simplemente en un perjuicio en la valoración suficiente y consecuente que se haga de la prueba ( $\$ \$ 371$ Abs. 3, 427, 444 ZPO.). Ello no tendrá lugar cuando el contra interés de la parte procesal que debiera soportar esta consecuencia perjudicial -frecuentemente la pérdida del proceso- no esté suficientemente justificado. Ello siempre que existan causales que justifiquen la negativa y que puedan por ejemplo liberar un tercero del deber $^{46}$.

\section{NUEVOS CRITERIOS INTERNACIONALES}

\section{1. "Principles of Transnational Civil Procedure" (2004).}

El completo sistema procesal alemán en materia de esclarecimiento procesal de los hechos se encuentra como siempre atrasado en relación al desarrollo internacional. Ello puede apreciarse claramente cuando se parte de parámetros como los aprobados Principles of Transnational Civil Procedure, de Unidroit y el American Law Institute, de 2004 (por cierto con voto aprobatorio alemán $)^{47}$. Ellos prevén con toda claridad el

\footnotetext{
${ }^{44}$ Así ver MusielaK - Stadler, cit. (n. 32), $\$ 142$ n. 7

${ }^{45}$ Ello es irrelevante para la interpretación del ZPO. alemán [STEIN - JONAS - LEIPOLD, cit. (n. 16) $\$ 138$ No 23a], en su generalidad es difícil de representárselo.

${ }^{46}$ En relación a este problema ver ya en STÜRNER, Rolf, Aufklärungspflicht, cit. (n. 2), pp. 174 ss., 180 ss., 198 ss.; El mismo, en Rabels Zeitschrift, cit. (n. 19), pp. 201 ss., 242 ss.

${ }^{47}$ En forma completa: STÜRnER, Rolf, en Rabels Zeitschrift, cit. (n. 19), pp. 201 ss., 341 ss.
} 
deber de las partes y de terceros, igualmente garantizan el acceso a todos los medios de prueba relevantes ${ }^{48}$. La protección frente a excesos para el logro del esclarecimiento se logra - y en ello siguiendo a la tradición continental- garantizando que, para el esclarecimiento sean requisitos todas aquellas alegaciones de hechos sustanciadas ("fact pleading") y la individualización de los medios de prueba ${ }^{49}$. Recién cuando una parte pueda demostrar con buenos motivos que no es posible una sustanciación plena o que excepcionalmente no es posible la individualización del medio de prueba, el tribunal igualmente podrá ordenar a una parte su aclaración sobre la base de las alegaciones generales que se hicieron valer ${ }^{50}$. Las sanciones son medios directos de coerción o valoraciones probatorias negati$\operatorname{vas}^{51}$. En el caso que existan los tradicionales motivos para una negativa, los que típicamente se encuentran establecidos para testigos y terceros, no tiene lugar la coerción inmediata. En relación a las partes, el tribunal debe ponderar los motivos de la negativa a cooperar cuando deba decidir sobre una valoración probatoria perjudicial para aquellas ${ }^{52}$. Las medidas provisorias o cautelares preprocesales abarcan también el aseguramiento forzoso y localización de medios de prueba ${ }^{53}$. Las conductas preprocesales contrarias al esclarecimiento pueden ser sancionadas de acuerdo a determinados montos en forma de costos económicos ${ }^{54}$.

\section{El movimiento dentro de la Unión Europea.}

Dentro de la Unión Europea se alza también una mayor presión para la ampliación o manejo generoso de las posibilidades de esclarecimiento. Se inicia así la clara tendencia, mediante las directivas dentro de la Unión Europea indicando la necesidad del fortalecimiento y mayores posibilidades de esclarecimiento procesal en áreas especiales de los Estados miembros. Ello lo deja claro la Directiva para el establecimiento de la propiedad intelectual (artículos 6-8 Dir.) ${ }^{55}$, como así también el nuevo libro verde de la Comisión sobre Demandas de indemnización por Violación del Derecho

\footnotetext{
${ }^{48}$ Principle 16.

${ }^{49}$ Principles 11.3 , párrafo 1 y 16.2.

${ }^{50}$ Principle 11.3, párrafo 2.

${ }^{51}$ Principle 17.

${ }^{52}$ Principle 18; al respecto STÜRnER, Rolf, en Rabels Zeitschrift, cit. (n. 19), pp. 201 ss., 241 ss.

${ }^{53}$ Principle 8.1 ver el comentario "Comment".

${ }^{54}$ Principles 17.3 y 25.2 .

${ }^{55}$ Ver en forma completa Haedicke, cit. (n. 32), pp. 19 ss.
} 
de la competencia comunitaria, el que dedica una atención especial a las posibilidades probatorias ${ }^{56}$.

\section{CONCLUSIONES: EL AÚN PERMANENTE DÉFICIT ALEMÁN}

Cuando se analiza críticamente el proceso alemán desde la perspectiva ya descripta del desarrollo nacional e internacional, aun se pueden observar varias deficiencias incluso con el movimiento de reformas de los dos últimos ańos. Déficit cuya eliminación sería recomendable y necesaria ya por el legislador, ya por la jurisprudencia.

\section{Fase preprocesal.}

a) Sanción con costos para la vulneración de los deberes de información y conservación de documentos y medios de prueba. En la etapa previa al proceso se manifiestan fortalecimientos mediante sanciones con costos en relación a los deberes de información con algún parecido al modelo inglés. Se tiende así a evitar reducir la información relativa a la controversia ${ }^{57}$. De la misma manera una moderna regulación de deberes procesales de documentación y conservación de medios probatorios debiera eliminar el por cierto muy limitado $\$ 444 \mathrm{ZPO} .{ }^{58}$.

b) Pretensiones fundadas en el derecho material y medidas cautelares. Aún con la ampliación de los deberes preprocesales de información contenidos en el derecho material existen deficiencias, las que pueden tener efectos negativos especialmente en el área de determinados derechos comerciales protegidos ${ }^{59}$ como en el ámbito de los delitos económicos (violación de la competencia, violación de normas en materia de título de valores etc.). Aun cuando el establecimiento procesal de pretensiones de información del derecho material pueda conducir con frecuencia a una duplicación procesal, los deberes de esclarecimiento intraprocesales lo evitan en la misma manera como si fueran deberes preprocesales sancionables con determinados costos económicos. Dicha pretensiones reguladas en el derecho material pueden sin embargo asegurarse mediante medidas provisorias cautelares que permitan el acceso a la conservación del medio de prueba ( $\$ 938$ ZPO.). En forma conjunta con la petición de aseguramiento de la prueba ( $\$ \$ 485$ ss. ZPO.) es posible arribar al esclarecimiento

${ }^{56} \mathrm{KOM}$ (2005) 672 versión final del 19 de diciembre de 2005, sub 2.1.

${ }^{57}$ De la misma forma Greger, cit. (32), pp. 848 s.; en forma completa Breyer, cit. (n. 25) \ 12 B II 2; ya con anterioridad STÜRNER, Aufklärungspflicht, cit. (n. 1), pp. 273 ss.

${ }^{58} \mathrm{Al}$ respecto: STÜRner, Aufklärungspflicht, cit. (n. 1), p. 384.

${ }^{59} \mathrm{Al}$ respecto Haedicke. cit. (n. 32), pp. 19 ss., 28 ss., 31 s. 
de los hechos permitiendo entonces una resolución plena sobre el "si" y el "cómo" de un proceso ${ }^{60}$. Se puede discutir sobre los requisitos de dichas pretensiones. Sin embargo ello se convierte en armas sin filo cuando se establece como requisito frente a las partes o terceros la violación del derecho a determinarse, no siendo suficiente la verosimilitud, lo que finalmente debe ser evaluado por el tribunal que conoce ${ }^{61}$.

c) Declaración testimonial escrita. También pertenece a la etapa preprocesal la posibilidad amplia de declaraciones escritas de testigos. De acuerdo a la concepción alemana, el juez así lo puede requerir a lo largo del proceso (\$377 párr. $3 \mathrm{ZPO}$.). El abogado que solicita a un testigo dicha declaración, aun cuando no actúe incorrectamente - esto contra una divulgada visión que opina lo contrario ${ }^{62}$, se corre el peligro de que se sospeche de "witness coaching" arribando la valoración del testigo contrario a la parte en cuyo favor declara ${ }^{63}$. El escepticismo contra todo tipo de declaración por escrito temprana de testigos al considerarse influenciados por las partes y sus abogados está muy difundido en Alemania. Así en la práctica forense incluso la orden judicial para su producción es muy reticente y excede en prudencia. Si esto es correcto y se condice con la realidad de búsqueda por la parte del "testigo adecuado" es otra pregunta. Esto también podría verificarse en el mundo santo y virginal del testigo oral que perfectamente puede ser engańoso y solo una mera apariencia. De acuerdo al modelo inglés es mucho más conveniente dejar todo fijado por escrito en la etapa preprocesal ${ }^{64}$, para poder así proteger la declaración de influencias ajenas a la causa y evitar cambios en ella.

\section{Esclarecimiento procesal interno.}

En relación al esclarecimiento dentro del proceso aun cuando la Reforma 2002 ha efectuado un importante avance, se quedó temerosa a mitad del camino.

a) Eliminación del doble contenido. Vinculado a la regulación de los deberes de cooperación los actuales dos carriles existen que emergen del infundado temor ( $\$ \$ 142$ ss.; 373 ss.; 422 ss. ZPO.). Explicamos esto. La orden para requerir el esclarecimiento a pedido de parte o de oficio

${ }^{60}$ En relación con este tema: HaEdicke, cit. (n. 32), pp. $26 \mathrm{~s}$.

${ }^{61}$ En una misión correcta BGHZ 150, 377 ss., 384 ss. ("Faxkarte“).

${ }^{62}$ En forma completa Timmerbeil, cit. (n. 11), pp. 119 ss.

${ }^{63}$ Murray - Stürner, cit. (n. 11), pp. 294-295.

${ }^{64} \mathrm{Al}$ respecto Principles of Transnational Civil Procedure, Principle 16.3, en Rabels Zeitschrift, cit. (n. 19), 341 ss., 346; más en detalle STÜRner, en Rabels Zeitschrift, cit. (n. 19), pp. 201 ss., 236. 
implica que ambas posibilidades deben tener igual cobertura ${ }^{65}$, ya que incluso en casos controvertidos decide el tribunal a requerimiento de parte. De esta forma el temor al exceso para escudriñar y obtener información en forma abusiva aparece como totalmente infundado desde la óptica de la experiencia de los países europeos vecinos. Esto no debiera ocurrir en caso de que -teniendo presente lo contemplado en la ZPO.- se regulen los límites considerando los principios de las alegaciones de las partes que sean sustanciales y bases de determinadas pruebas. Así, y sólo en casos excepcionalmente fundados, sería posible permitir el esclarecimiento sobre alegaciones generales y ordenar la presentación de medios probatorios en conjunto.

b) Necesidad de la incorporación de una cláusula general de cooperación. De acuerdo al modelo francés se debiera incluir en la ZPO. una cláusula general que imponga a las partes deberes sancionados con perjuicios para que éstas cumplan con los aportes de esclarecimiento exigibles $^{66}$. De esta forma un gran número de deberes tendrían un fundamento legal, el que de hecho actualmente la jurisprudencia lo aplica con gran inseguridad. Así por ejemplo la carga del esclarecimiento sobre hechos acaecidos en el ámbito de la propia esfera, que no puede ser conocida por la contraparte que tiene la carga de la prueba; o en los supuestos de liberación de los deberes impuestos de confidencialidad; deber de inspección medicinal, etc.

c) Audiencia y declaración de partes. La audiencia ( $\$ 141$ ZPO.) y declaración de partes ( $\$ \$ 445$ ss. ZPO.) debieran ser armonizadas como medios de esclarecimiento. Se debiera eliminar la subsidiariedad de la declaración de partes actualmente existente, como así también la limitación consistente en exigirse petición de la contraparte $(\$ \$ 445,448 \mathrm{ZPO} .)^{67}$. Así de esta forma es posible adecuarse a los requerimientos del Tribunal Europeo de Derechos Humanos ${ }^{68}$.

\section{Publicidad para las partes y reserva por secreto.}

Sin duda la publicidad para las partes de cada uno de los hechos alegados $(\$ 357$ ZPO.) es un pilar fundamental del proceso del Estado de Derecho en los términos de las garantías procesales del artículo 103 GG. ("Ley Fun-

${ }^{65}$ Musielak - Stadler, cit. (n. 32)., $\$ 142$ No 7.

${ }^{66} \mathrm{Al}$ respecto artículo 10 Code Civil y artículo 11 Nouveau Code de Procédure Civile; igualmente GotTwald, Peter, Gutachten, cit. (n. 38), pp. A 15-21; ya con anterioridad STÜrner, Aufklärungspflicht, cit. (n. 1), p. 384.

${ }^{67}$ En este sentido: Coester - Waltjen, cit. (n. 6), pp. 269 ss., 289 ss., 293.

${ }^{68}$ Tribunal Europeo de Derechos Humanos, en Neue Juristen Wochenschrift (1995), p. 1413. 
damental") como así también del artículo 6 Abs. 1 de la "Carta Europea de Derechos Humanos". Siendo que en este ámbito de los intereses personales confidenciales (ej. inspección médica) o de secretos comerciales (ej. rendición de prueba sobre un procedimiento de producción, esquema de cálculo o red de clientes, etc.) la publicidad de la prueba se excluye en relación a terceros ( $\$ \$ 383,384$ ZPO.). O igualmente es de esperarse para una de las partes, luego de una debida y necesaria ponderación, que la confidencialidad pueda incluso conducirse frente a la contraparte. Esto resulta totalmente carente de problemática, cuando la parte que tiene la carga de la prueba puede acceder a los medios de prueba de la contraparte o de terceros, si es que aquella renuncia a tomar un conocimiento pleno. Así en realidad se encontraría frente a una opción, u obtener una tutela limitada o bien ninguno de sus derechos, de todas formas siendo que su renuncia a una publicidad plena resulta totalmente acorde con el artículo 103 Abs. 1 GG. ("Ley Fundamental") o el artículo 6 párr. $1(\mathrm{CEDH} .)^{69}$, la discusión sobre el "proceso secreto" resulta difícil de imaginar, al menos en esta variante casuística ${ }^{70}$.

Allí donde la parte que tiene la carga de la prueba tenga interés en que la prueba propia y pero conducida por la contratraparte se mantenga en confidencialidad parcial y así poder resguardar su propio secreto, la ponderación resulta algo dispar y difícil. De igual forma el Tribunal Constitucional Federal (BverfG) también ha considerado en dicho casos como opinable dicha solución considerad ${ }^{71}$. El legislador alemán debiera más bien regular el "proceso secreto" de acuerdo a los modelos de otros sistemas jurídicos ${ }^{72}$. Así por ejemplo en los casos que el tribunal adquiere un pleno conocimiento participando solamente un perito con deber de confidencialidad, la contraparte solamente conoce el tipo de prueba requerida solo en sus resultados. Actualmente es justo y necesario en el área

${ }^{69}$ En este sentido y primero por cierto STÜRNER, Aufklärungspflicht, cit. (n. 1), pp. 223 ss.; El mismo, en Juristen Zeitung (1985), p. 453; Schlosser, Zivilprozessrecht, cit. (n. 32), I, No. 430; STADLER, en Neue juristischen Wochenschrift (1989), pp. 1202 ss.; hoy como posición mayoritaria: RosenberG - SCHWAB - GotTWALd, cit. (n. 18), $\$ 115$ V 3, p. 800 en detalle; WAGNer, Gerhard, Datenschutz im Zivilprozess, en Zeitschrift für Zivilprozess 108 (1995), pp. 193, 212 ss.

${ }^{70}$ En contra BGHZ 116, 47, 58; en sentido contrario a la pretensión de información de derecho BGHZ 150, 377, 387; otro punto de vista por ejemplo PrüTtING, Hans - Weth, Stephan, Geheimnisschutz im Prozeßrecht, en Neue juristischen Wochenschrift (1993), p. 576; Prütting, Hans, MünchKommZPO (München, 2002), $\$ 286$ n. 11

${ }^{71} \mathrm{Al}$ respecto BVerfG, en Neue juristischen Wochenschrift (1994), p. 2347; BVerfG 91, 176 ss., 181 ss.

${ }^{72} \mathrm{Al}$ respecto Stadler, Schutz des Unternehmensgeheimnisses, cit. (n. 32), pp. 222 ss., 254 ss.; WaGner, cit. (n. 70), pp.193 ss., 210 ss. 
de tutela de derechos comerciales y propiedad intelectual donde el silencio del legislador conduce a mucha inseguridad a los tribunales, requiriendo una protección clara y confiable.

[Recibido el 28 de abril y aceptado el 5 de mayo de 2008].

\section{BIBLIOGRAFÍA}

Andrews, Neil, Englisch Civil Procedure (Oxford, 2003).

Arens, Peter, Zur Aufklärungspflicht der nicht beweisbelasteten Partei im Zivilprozeß, en Zeitschrift für Zivilprozess 96 (1983).

Arens, Peter, Zur Aufklärungspflicht der nicht beweisbelasteten Partei im Zivilprozess, en Zeitschrift für Zivilprozess 96 (1983).

Baur, F., Zivilprozessrecht (6a edición, Tübingen, 1989).

Breyer, Michael, Kostensanktionierte Steuerung des Zivilprozesses (Tübingen, 2006).

Coester - Waltjen, Dagmar, Parteiaussage und Parteivernehmung am Ende des 20. Jahrhunderts, en Zeitschrift für Zivilprozess) 113 (2000).

Friedenthal, Jack - Kane, Mary Kay - Miller, Arthur, Civil Procedure (3a edición, St. Paul, Minn, 1999).

GotTwald, Peter, Gutachten der 61. Deutschen Juristentag (1996).

Greger, Reinhard, Justizreform? Ja, aber..., en Juristenzeitung (2000).

Greger, Reinhard, Vom "Kampf ums Recht" zur Zivilprozess der Zukunft, en Juristen Zeitung (1997).

Gruber, Ulrich - KIEssling, Erick, Die Vorlagepflichten der SS 142 ff. ZPO. nach der Reform 2002, en Zeitschrift für Zivilprozess 116 (2003).

Grunsky, Wolfgang, Zivilprozessrecht (12a edición, Tübingen, 2006).

Haedicke, Maximilian, Perspektiven des gaeistigen Eigentums, Festschrift Schricker (München, 2005).

Hahn, Carl, Die gesamten Materialien zu den Reichsjustizgesetzen (2a edición, Berlin, 1881, reimpresión Berlin, 1983), II, 1.

Henckel, Wolfram, Wandel des Prozessverständnisses vom liberalen zum sozialen Zivilprozess? en Zeitschrift für Zivilprozess 92 (1979).

Katzenmeier Christian, Aufklärungs-Mitwirkungspflicht der nicht beweisbelasteten Partei im Zivilprozess, en Juristen Zeitung (2002).

KolLER, Versicherungsrecht (1990).

LANG, Jochanes, Die Aufklärungspflicht der Parteien des Zivilprozesses vor dem Hintergrund der europäischen Rechtsvereinheitlichung (Berlin, 1999).

LEIPOLD, Dieter, en Festschrift Gerhard (Tübingen, 2004).

LeIPOLD, en Festschrift Gerhard (Tübingen, 2004).

Lorenz, Stephan, Die Neuregelung der pre-trial-Discovery im US-amerikanischen Zivilprozessrecht: Inspiration für den deutschen und europäischen Zivilprozess? en Zeitschrift für Zivilprozess 111 (1998).

Lüke, Gerhard., Der Informationsanspruch im Zivilrecht, en Juristische Schulung (1986).

LüKE, Wolfgang, Die Zuständigkeitsprüfung nach dem EuGV., en Gedächtnisschrift Arens (München, 1993). 
Lüpke - Müller, Pre-Trial Discovery of Documents " und S 142 ZPO., en Neue Zeitschrift f. das Recht der Insolvenz und Sanierung (2002).

Murray, Meter - Stürner, Rolf, German Civil Justice (North Carolina, 2004).

Oberhammer, Paul, Parteiaussage, Parteivernehmung und freie Beweiswürdigung am Ende des 20. Jahrhunderts, en Zeitschrift für Zivilprozess 113 (2000).

Polyzogopoulos, Konstantin, Parteianhörung und Parteivernehmung (Berlín, 1976).

Principles of Transnational Civil Procedure, en Rabels Zeitschrift ausländisches und internationales Privatrecht 69 (2005).

Prütting, Hanns, Gegenwartsprobleme der Beweislast (München, 1983).

Prütting, Hans - Weth, Stephan, Geheimnisschutz im Prozeßrecht, en Neue juristischen Wochenschrift (1993).

Prütting, Hans, MünchKommZPO (München, 2002).

Rosenberg, Leo - Schwab, Karl - Heinz - Gottwald, Peter, Zivilprozessrecht (16a edición, München, 2004).

Rотн, Herbert, Die Vorschläge der Kommission für ein europäisches Zivilprozeßgesetzbuch. Das Erkenntnisverfahren, en Zeitschrift für Zivilprozess 109 (1996).

Rотн, Herbert, Rezension, en Zeitschrift für Zivilprozess 113 (2000).

Roxin, Klaus, Strafverfahrensrecht (25ª edición, München, 1998).

Sснаск, Haimo, Einführung in das US-amerikanische Zivilprozessrecht (3a edición, München, 2003).

Schlosser Peter, Die lange deutsche Reise in die prozessuale Moderne, en Juristen Zeitung (1991).

Schlosser, Peter, Die lange deutsche Reise in die prozessuale Moderne, en Juristen Zeitung (1991).

Schlosser, Peter, Zivilprozessrecht (2a edición, München, 1991), I

SchmidT, Joachim, Alternativ-Kommentar ZPO. (Saarbrücken, 1987).

STADler, Astrid, Gruppenklagen in den Mitgliedstaaten der Europäischen Gemeinschaft, en Festschrift Beys (Atenas, 2003), II.

STADLER, Astrid. Schutz des Unternehmensgeheimnisses im deutschen und US-amerikanischen Zivilprozess und im Rechtshilfeverfahren (Tübingen, 1989).

Stein, Friedrich - Jonas, Martin - LeIpold, Dieter, Comentar zur Zivilprozessordnung (21ª edición, Tübingen, 1993).

STÜRNER, Rolf, Anmerkung zum Urteil des BGH v. 11.6.1990 (Aufklärungspflicht der nicht beweisbelasteten Partei im Zivilprozeß), en Zeitschrift für Zivilprozess 104 (1991).

STÜRNER, Rolf, Beweislastverteilung und Beweisführungslast in einem harmonisierten europäischen Zivilprozeß, en Festschrift Stoll (Tübingen, 2001).

Stürner, Rolf, Die Aufklärungspflicht der Parteien des Zivilprozesses (Tübingen, 1976).

STÜRnER, Rolf, Die Partei als Beweismittel im europäischen Zivilprozeß, in Festschrift Ishikawa (Berlin, 2001).

STÜrner, Rolf, The Principles of Transnational Civil Procedure. An Introduction to Their Basic Conceptions, en Rabels Zeitschrift ausländisches und internationales Privatrecht 69 (2005).

STÜRNER,, en Juristen Zeitung (1985).

Timmerbeil, Sven, Witness Coaching und Adversary System (Tübingen, 2004).

Triebel, Volker - Zons, Jan, Befragung von Zeugen vor dem Hearing in Unternehmen- 
sinsolvenzrechts durch den Enterprise Act, en Recht der Internationalen Wirtschaft 3 (2002).

Trittmann, Rolf - Leitzen, Mario, Haager Beweisübereinkommen und pre-trial discovery, en Iprax. Praxis des Internationalen Privat- und Verfahrensrechts (2003).

Wagner Gerhard, Europäisches Beweisrecht. Prozeßrechtsharmonisierung durch Schiedsgerichte, en Zeitschrift für Europäisches Privatrecht (2001).

WAGNer, Gerhard, Datenschutz im Zivilprozess, en Zeitschrift für Zivilprozess 108 (1995).

Waterstraat, Daniel, Informationspflichten der nicht risikobelasteten Partei im Zivilprozess, en Zeitschrift für Zivilprozess 118 (2005).

Zeкoll, Joachin - Bolt, Jan, Die Pflicht zur Vorlage von Urkunden im Zivilprozess, en Neue juristische Wochenschrift (2002).

Zuckerman, Adrian, Civil Procedure (Oxford, 2003). 